Boletín de la Sociedad Geológica Mexicana

VOLUMEN 65, NÚM. 1, 2013, P. 71-82

\title{
Comportamiento hidrogeoquímico de flujos subterráneos en acuíferos cársticos fracturados, aplicando modelación inversa: Caso Huasteca Potosina
}

\author{
Janete Morán-Ramírez ${ }^{2}$, José Alfredo Ramos-Leal ${ }^{1, *}$, Briseida López-Álvarez ${ }^{2,3}$, \\ Simón Carranco Lozada ${ }^{2}$, Germán Santacruz-De León ${ }^{3}$ \\ ${ }^{1}$ Instituto Potosino de Investigación Científica y Tecnológica, A.C. (IPICYT), C. Presa San José \# 2055, Lomas 4a sección, C.P. \\ 78216, San Luis Potosí, San Luis Potosí, México. \\ ${ }^{2}$ Posgrado en Geociencias Aplicadas. Instituto Potosino de Investigación Científica y Tecnológica, A.C. (IPICYT), C. Presa San José \\ \# 2055, Lomas 4a . Sección, CP 78216, San Luís Potosí, SLP, México. \\ ${ }^{3}$ Programa Agua y Sociedad. Colegio de San Luis, A. C. (COLSAN). Parque de Macul No. 155, Fracc. Colinas del Parque, San Luis \\ Potosí, S.L.P. México, C.P. 78299. \\ *jalfredo@ipicyt.edu.mx
}

\section{Resumen}

El área de estudio se encuentra dentro de la Plataforma Valles-San Luis Potosí la cual pertenece a la Sierra Madre Oriental (SMO), cuya porción montañosa formada por anticlinales y sinclinales tienen una orientación preferencial NW-S y un sistema muy importante de fallas y fracturas con orientación E-W que controlan el flujo subterráneo hacia el Golfo de México. Para demostrar la conectividad hidráulica del sistema de fallas y fracturas E-W, se aplicó modelación inversa en cuatro secciones, otras pruebas realizadas a posibles conexiones entre fracturas no fueron capaces de reproducir estos procesos, lo que se interpreta como puntos sin conexión hidráulica. Se identificaron dos principales tipos de agua: uno bicarbonatado cálcico debido a interacción con rocas carbonatadas como las calizas y otro sulfatado cálcico que se relaciona con un proceso de interacción agua-roca, principalmente de origen evaporítico como los yesos. En el trayecto de Rioverde a Santa Anita, el agua subterránea disminuye su composición química debido a un proceso de dilución por mezcla con otras aguas de reciente infiltración o menos evolucionadas por lo que sus parámetros fisicoquímicos disminuyen. El flujo subterráneo de Apesco a Huichihuayan muestra un incremento en sus parámetros fisicoquímicos debido a la disolución de yeso, calcedonia y dolomita; así como, precipitación de anhidrita, aragonita, calcita, halita y celestita. La evolución hidrogeoquímica de Unión de Guadalupe a Tambaque muestra un incremento de los parámetros fisicoquímicos por la disolución de calcita, fluorita, halita, sílice, azufre; así como, precipitación de dolomita. En la sección El Salto- Minas Viejas, se relaciona con la disolución de calcita, pirita y cuarzo, junto con la precipitación de celestita, dolomita, FeS, yeso, halita y jarosita.

Palabras clave: modelación hidrogeoquímica, modelación inversa, balance de masas, conectividad hidráulica, índices de saturación, karst, precipitación y disolución.

\begin{abstract}
The study area is located inside the Valles-San Luis Potosi platform, which belongs to the Sierra Madre Oriental (SMO), whose mountain portion, formed by anticlines and synclines, has a North-South preferential orientation and a very important system of faults and fractures with East-West orientation that control the groundwater flow into the Gulf of México. In order to demonstrate the hydraulic connectivity of the East-West system of faults and fractures, inverse modeling was applied to four sections. Other performed tests in possible connections between fractures were not able to reproduce these processes, which are interpretated as non-hydraulic connection points. Two main types of water were identified: one with calcium bicarbonate because of the interaction with carbonate rocks such as limestone, and other with calcium sulfate that is related with a process of water-rock interaction, mainly from evaporite
\end{abstract}


origin such as plaster. On the flow path to Rioverde-Santa Anita, groundwater decreases its chemical composition due to a process of dilution by mixing with recent water infiltration or less evolved so their physicochemical parameters decrease. The flow path from Apesco to Huichihuayán shows an increase in their physicochemical parameters due to the dissolution of gypsum, chalcedony and dolomite, as well as precipitation of anhydrite, aragonite, calcite, halite and celestite. The hydrogeochemical evolution of Union de Guadalupe to Tambaque shows an increase in the physicochemical parameters for the dissolution of calcite, fluorite, halite, silica, sulfur, as well as precipitation of dolomite. The Salto-Minas Viejas flow section is related to the dissolution of calcite, pyrite and quartz, accompanied by the precipitation of celestite, dolomite, FeS, gypsum, halite, jarosite.

Keywords: hydrogeochemical modeling, inverse modeling, mass balance, hydraulic connectivity, saturation index, karst, hydrogeochemical facies, precipitation and dissolution.

\section{Introducción}

La composición química del agua subterránea que no se ha mezclado es controlada principalmente por factores como tiempo de residencia, distancia recorrida, mineralogía y geología del acuífero. La distribución espacial de los parámetros fisicoquímicos en el agua subterránea da una idea de la heterogeneidad y la conectividad del subsuelo por donde circula el agua. Ésta puede fluir por acuíferos en medio granular o en medio fracturado karstificados. En el primer caso el flujo es laminar, en tanto que el flujo subterráneo en medios fracturados se caracteriza por tener velocidades altas y heterogéneas, tiempos de residencia relativamente cortos y gran interacción agua-roca (Roback et al., 2001).

Durante el trayecto del flujo subterráneo ocurren procesos hidrogeoquímicos como el intercambio iónico, reacciones ácido-base, procesos óxido-reducción, disolución, precipitación, posibles mezclas de aguas, reducción bacteriana y degradación.

Una forma de conocer los procesos hidrogeoquímicos es mediante la aplicación de modelos numéricos los cuales proporcionan información detallada acerca de su origen, interacción agua-roca y patrones de flujo (Hidalgo y CruzSanjulián, 2001).

La modelación directa y la modelación inversa son dos tipos de modelaje hidrogeoquímicos en donde se aplican los principios físico-químicos para describir las reacciones que ocurren en el sistema hidrológico (Parkhurst et al., 1980). La primera, predice la composición del agua y la transferencia de masa que puede resultar de reacciones químicas hipotéticas; mientras que la segunda, se define como la transferencia de masas a partir de datos químicos, isotópicos y mineralógicos observados, intentando explicar el significado de un conjunto de datos hidrogeoquímicos e identificar de forma cuantitativa la reacciones hidrogeoquímicas que dan origen a dicha composición (Parkhust y Apello, 1999).

La modelación inversa permite cuantificar las fases de reacción gaseosa, mineralógica y acuosa en cantidades apropiadas a fin de determinar las diferencias entre los productos inicial y finales de las soluciones (Parkhust y Apello, 1999).

Ambos modelos hidrogeoquímicos utilizan reacciones químicas específicas como intercambio iónico, reacciones ácido-base, procesos óxido-reducción, disolución, precipitación, posibles mezclas de agua; así como reducción bacteriana los cuales pueden ocurrir en el trayecto del flujo subterráneo.

Los cálculos inician con la composición inicial del agua, a partir de la cual se realiza una especiación para obtener los índices de saturación presentes en la solución, su composición determina la distribución de las especies presentes en la solución, actividad termodinámica, así como, el estado de saturación de la solución con respecto a las distintas fases minerales. Finalmente se calcula con códigos numéricos la transferencia de masa entre una fase sólida y la fase acuosa en equilibrio, este proceso de interacción agua-roca es reversible (Plummer y Back, 1980; Apello y Postma, 1996). Como resultado se obtiene la composición del agua, identificación de la roca con la que reacciona en el sistema en equilibrio (evolución composicional) y las solubilidades de los minerales, así como, la transferencia de masa entre distintas fases (Helgeson et al., 1970; Hereford et al., 2007). Una manera simple de ejemplificar este proceso es con la siguiente ecuación.

Agua inicial + reactivos $=$ agua final + productos

Agua inicial es la composición del agua en el punto origen, el reactivo es el medio rocoso con el que interactúa, el agua final y los productos son el resultado de los procesos de interacción con el medio.

La modelación inversa se aplica entre dos puntos, los cuales se infiere que están a lo largo de una línea de flujo. Se supone una composición inicial y una final (puntos extremos). Para la aplicación del modelo se parte de la premisa de que existen diferencias en los componentes químicos de ambos puntos (delta iónico). El modelo cuantifica los procesos que son posibles; para explicar los cambios observados sobre una línea de flujo; además, calcula todos los posibles conjuntos de reacciones entre puntos extremos y la fase mineral definida (André et al., 2005). Cabe mencionar que la conectividad entre dos puntos no siempre es posible.

En el presente trabajo se utiliza la modelación hidrogeoquímica inversa para demostrar la conexión hidráulica existente entre pares de manantiales; como Apesco-Huchihuayan, Unión de Guadalupe-Tambaque, 
Rioverde-Santa Anita, El Salto-Minas Viejas, localizados en la parte cárstica de la Huasteca Potosina.

La Huasteca Potosina se encuentra en la parte central de la Sierra Madre Oriental; está integrada principalmente por calizas plegadas y fracturadas formando valles intermontanos (Figura 1). El área de estudio se considera parte de la zona de descarga de la Sierra Madre Oriental.

En general se conoce poco sobre el funcionamiento hidrodinámico de los sistemas kársticos en la SMO, debido a que son difíciles de estudiar por las condiciones abruptas del terreno y la excesiva vegetación; así como, a la ausencia de pozos de extracción para su estudio.

\section{Descripción del área de estudio}

El área de estudio también conocida como Plataforma Valles-San Luis Potosí (PV-SLP), pertenece a la Sierra Madre Oriental, cuya porción montañosa formada por anticlinales y sinclinales tienen una orientación preferencial NW-SE.

Las edades de las rocas que afloran en el área de la PV-SLP varían del Mesozoico al Reciente (Figura 2). Las rocas más antiguas dentro del Mesozoico corresponden al Cretácico Inferior, constituido por depósitos evaporíticos, (principalmente yesos de la Formación Guaxcama) cabe mencionar que estas rocas afloran al $\mathrm{W}$ del área de estudio.

El Cretácico Inferior se depositó fuera de la PV-SLP, consiste de calizas compactas de textura fina, con nódulos de pedernal perteneciente a la Formación Tamaulipas Inferior de facies batial. Al interior de la PV-SLP se desarrolló en un ambiente evaporítico la Formación Guaxcamá, cuyo espesor es mayor a los $2000 \mathrm{~m}$, como lo indica el pozo Lagunillas, perforado por PEMEX (CRM, 1992). En el Cretácico medio fue depositada la Formación El Abra en un ambiente lagunar con su correspondiente frente arrecifal y en los bordes exteriores se acumularon restos del mismo que dieron origen a la Formación Tamabra, el espesor de la Formación El Abra varía de 1500 - 2000 m, (Carrillo y Suter, 1982). El Cretácico Superior involucra un número más variado de formaciones las cuales cambian dependiendo de la posición que guardan dentro de la PV-SLP, la primera es la Formación Agua Nueva la cual está formada por una secuencia de caliza-lutita, por espesores aproximados de 80m (Padilla y Sánchez, 1985); ésta es cubierta por calizas arcillosas y margas de la Formación San Felipe, su espesor varia de 120 a 300m (Muir, 1936; CRM, 1992). Sobre esta última se encuentra la Formación Méndez compuesta por lutitas y capas delgadas de margas grises y azules, con un espesor no mayor de 70m (CRM, 1992).

Durante la formación de la Sierra Madre Oriental las rocas sedimentarias fueron plegadas originando formas alargadas y en posición paralela (anticlinales y sinclinales). El esfuerzo compresivo en las rocas sedimentarias produjo anticlinales con esfuerzos distensivos en sus crestas, generando un intenso fracturamiento. En algunos casos el plegamiento fue tal que produjo grandes cabalgaduras.

En general, existen dos sistemas estructurales (pliegues, fallas y fracturas) que afectan a las unidades cretácicas (Zapata-Zapata y Pérez-Benzor, 1979); uno es longitudinal que forma pliegues con orientación NW-SE y el otro es perpendicular a los ejes del plegamiento (Pérez-Corona,

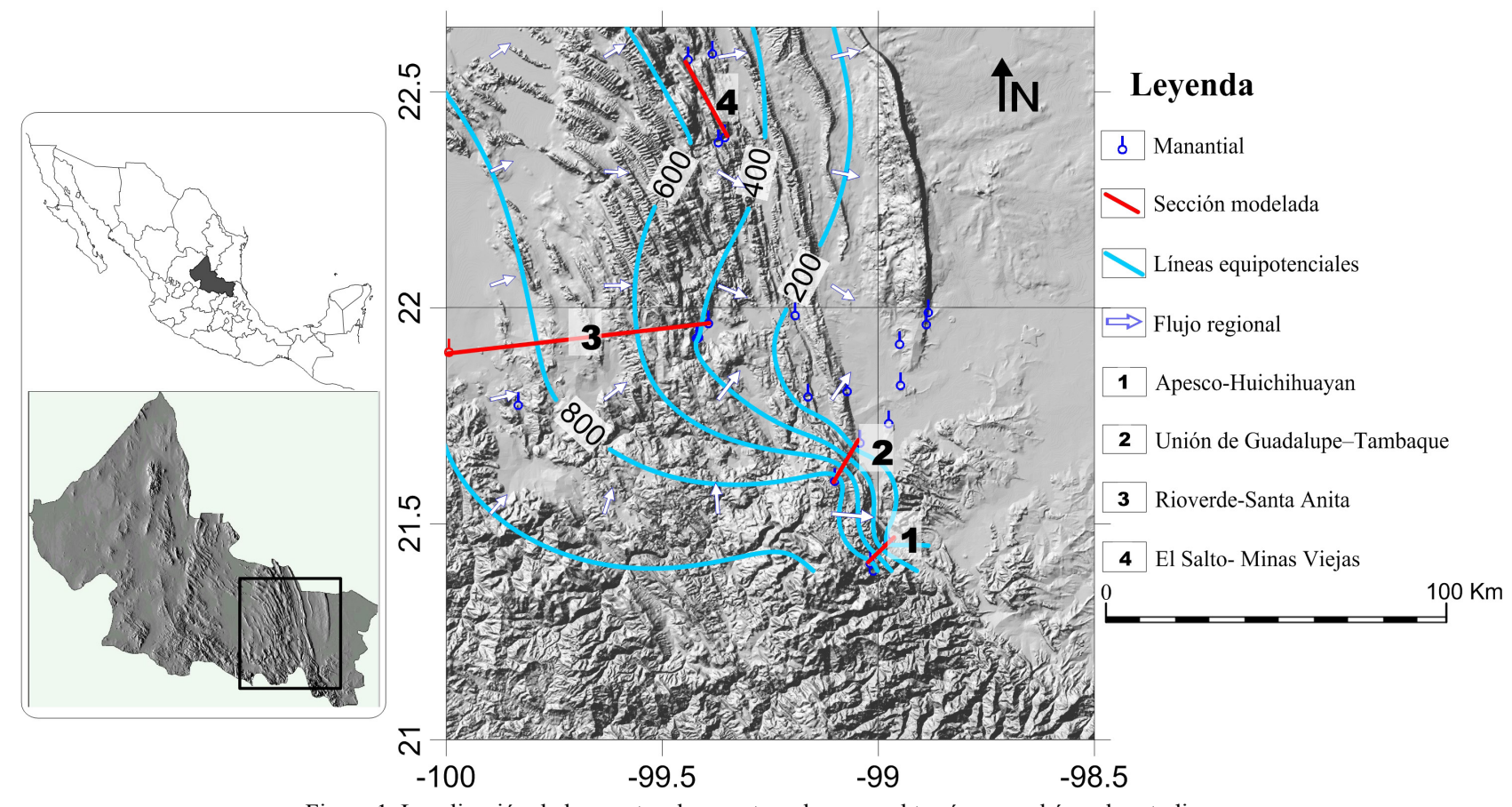

Figura 1. Localización de los puntos de muestreo de agua subterránea en el área de estudio. 


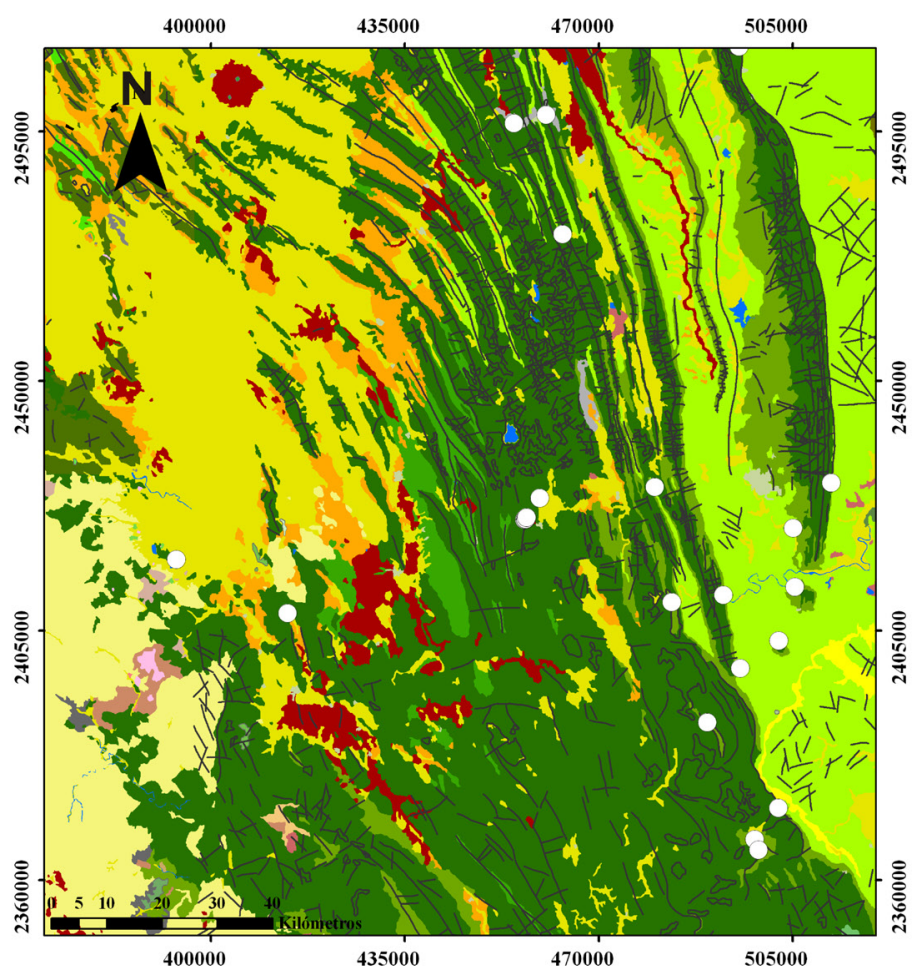

\section{CONTENIDO}

Muestras de agua subterránea

Alineamiento estructural Cuerpos de agua superficial Q(al) Aluvión

Q(ar) Arenisca

Q(B) Basalto

Ts(cg) Conglomerado

$\operatorname{Ts}(\mathbf{R})$ Riolita

Ts(R-Ta) Riolita-Toba ácida

Ts(Da) Dacita

Ks(lu) F. Méndez

Ks(lu-ar) F. Cárdenas

Ks(cz-lu) F. San Felipe

Ki(cz) F. Abra

Figura 2. Geología del área de estudio (Modificado de SGM, 1997).

2010). Las estructuras kársticas (dolinas, úvalas y poljes) se desarrollan en el sistema de pliegues NW-SE (Pérez-Corona, 2010). Posterior a la generación de este tipo de estructuras se produjeron fracturas y fallas normales con orientación E-W, que sirven de conducto entre los valles intermontanos (Ramos-Leal y Santacruz-De León, 2010).

\section{Hidrogeología}

A nivel regional el flujo subterráneo, va de las regiones de mayor elevación topográfica, localizadas en la Sierra de Álvarez de la zona media (2423 msnmm), a las de menor elevación hacia el Golfo de México en la zona de la Huasteca (Figuras 1 y 3).

En el área de estudio existen unidades con condiciones hidrogeológicas que funcionan como acuitardos (formaciones San Felipe y Méndez) y otros como acuíferos (formaciones Abra y Agua Nueva), esta última tiene poco espesor y no siempre está presente en la secuencia estratigráfica debido a que fue erosionada.

La unidad hidrogeológica más importante de la región es la Formación El Abra, la cual está formada por carbonatos de plataforma y arrecifes, se encuentra muy fracturada y presenta las estructuras kársticas más importantes (dolinas) de la región, lo cual favorece la infiltración. La Formación El Abra se encuentra ampliamente expuesta en la región, por lo que generalmente se encuentra como acuífero libre (Figura 3). Sin embargo, en los valles se comporta como acuífero confinado, debido a que es cubierta por capas confinantes de las formaciones Méndez y San Felipe (Carranco-Lozada, 2011).

En general el agua fluye a través de las calizas en los valles y es captada principalmente por fallas regionales que descargan hacia el Golfo de México en la zona de la Huasteca (Figuras 1 y 3). Sólo en la parte interna de la PVSLP el flujo subterráneo interacciona con los yesos de la Formación Guaxcamá y es controlada por estructuras como anticlinales y sinclinales con orientación NW-SE y fallas regionales con una disposición E-W. Por lo que es posible suponer que el sistema de fallas E-W podría conectar la Zona Media con la Zona de la Huasteca (Ramos-Leal y Santacruz-De León, 2010).

\section{Metodología}

El muestreo fisicoquímico de este estudio se realizó en Agosto de 2008. Durante este periodo se tomaron 28 muestras de manantiales en época de estiaje en el sistema kárstico para determinar cationes y aniones mayoritarios (Figura 1). En época de lluvia se colectaron 5 muestras en sitios ya muestreados, para conocer el efecto de la mezcla meteórica en el sistema. Cabe mencionar que estas representan aproximadamente el $98 \%$ de los manantiales más importantes del área de estudio.

Todas las muestras de agua fueron colectadas en botellas de polietileno, (HDLP), lavadas y enjuagadas 7 veces con 


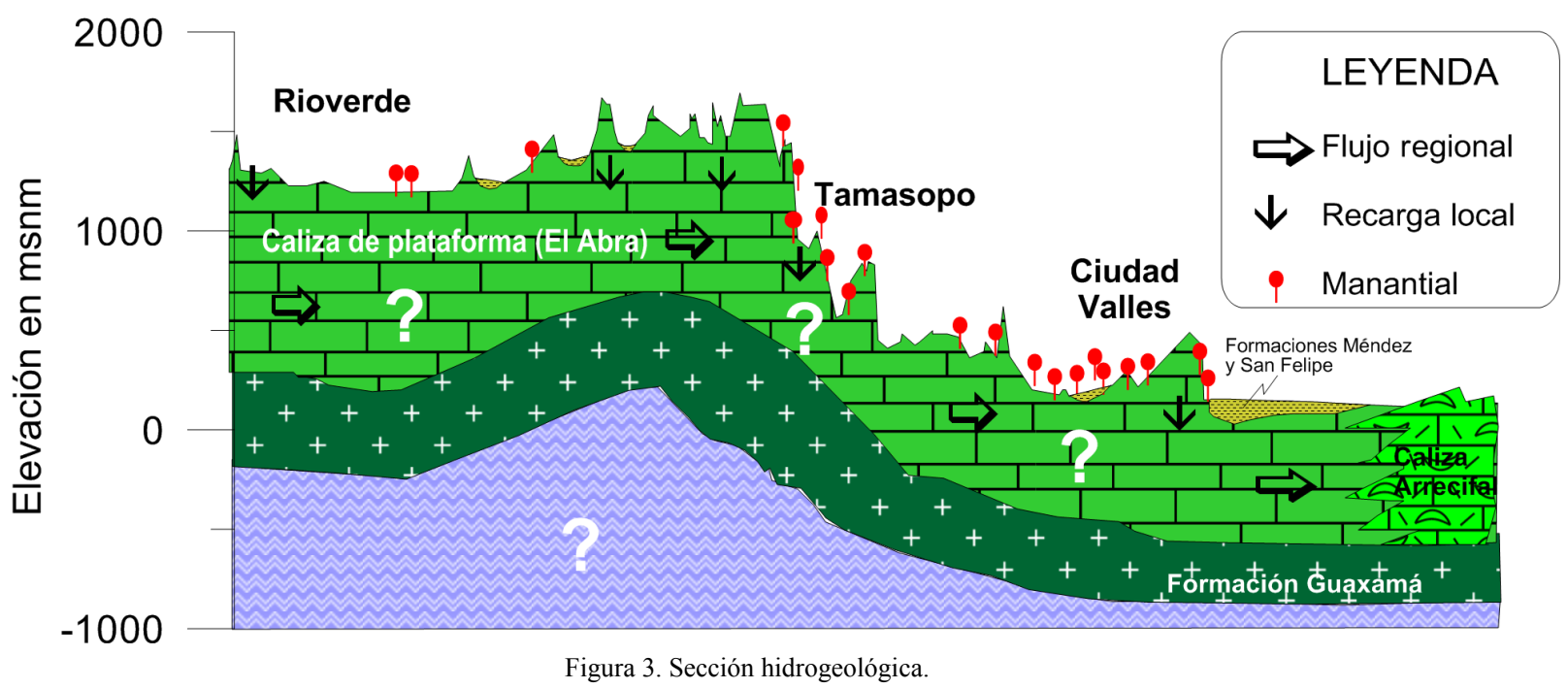

agua desionizada. Para colectar las muestras para determinar cationes y elementos traza, las botellas se lavaron además con $\mathrm{HCl} 10 \%$. Para cada muestra colectada, se midió in situ el $\mathrm{pH}$, conductividad eléctrica, temperatura, potencial redox (PR), oxígeno disuelto (OD) y alcalinidad.

Inmediatamente después de ser colectadas, las muestras para cationes y elementos traza se acidificaron con ácido nítrico puro hasta $\mathrm{pH}<2$. Todas las muestras se almacenaron a una temperatura menor a $4{ }^{\circ} \mathrm{C}$. Los iones mayores y elementos traza se analizaron en el laboratorio del Centro de Geociencias de la Universidad Nacional Autónoma de México. Las concentraciones de cationes mayores $\mathrm{Ca}^{2+}, \mathrm{Mg}^{2+}, \mathrm{Na}^{+}, \mathrm{y} \mathrm{K}{ }^{+}$fueron determinados por ICPOES y los aniones mayores $\left(\mathrm{SO}_{4}{ }^{2-} \mathrm{y} \mathrm{Cl}^{-}\right)$se analizaron usando cromatografía de líquido. La alcalinidad y $\mathrm{HCO}_{3}^{-}$se determinaron en el sitio por titulación. El error de equilibrio iónico (electro neutralidad) fue menor a $5 \%$ (Tabla 1 ).

Los índices de saturación $(S I=\log I A P / K$, donde $I A P$ es el producto de actividad de iónica y $K$ es el producto de solubilidad) con respecto a la calcita (SICa), aragonita (SIAr), dolomita (SIDo), yeso (SIGy), fluorita (SIF), y anhidrita (SIAn), fueron calculados con PHREEQC (Parkhurst y Apello, 1999).

\section{Resultados y Discusión}

\subsection{Facies Hidrogeoquímicas}

Las facies hidrogeoquímicas, tambien conocidas como familias de agua, pueden ser identificadas a partir de diferentes métodos. Los iones mayores de las muestras, tomadas en la zona de estudio, fueron gráficados un diagrama de Piper (Figura 4), un método gráfico cualitativo de identificación que, además, permite establecer la evolución hidrogeoquímica del agua subterránea.

En la figura 4, se identifican tres principales tipos de agua: 1) bicarbonatado cálcico $\left(\mathrm{Ca}-\mathrm{HCO}_{3}\right)$ característica de la interacción con rocas carbonatadas, 2) sulfatado cálcico $\left(\mathrm{Ca}-\mathrm{SO}_{4}\right)$ típico de la disolución de rocas evaporíticas con predominancia en yesos y 3) la transición entre las dos anteriores $\mathrm{Ca}-\mathrm{HCO}_{3}-\mathrm{SO}_{4}$ (Figura 4). La facie $\mathrm{Ca}-\mathrm{HCO}_{3}$, se distribuye principalmente en los valles de la zona de la Huasteca, en tanto que la facie $\mathrm{Ca}-\mathrm{SO}_{4}$ se encuentra en la zona montañosa de la Sierra Madre Oriental.

En el área de estudio ocurren principalmente dos procesos, la mezcla con agua meteórica y la interacción agua-roca (Figura 4). El pH del agua subterránea disminuye en época de lluvia y el agua disuelve más carbonatos, esto se observa con un incremento del índice de saturación (IS) para la dolomita y calcita; mientras que para la época de estiaje se tiene una disminución en solución debido a la precipitación de estos carbonatos. Si la mezcla con agua meteórica fuera predominante se tendrían valores bajos en los componentes fisicoquímicos debido a la dilución y los índices de saturación también serían bajos, pero si además se lleva al acabo la interacción agua-roca, se tendrá un incremento en los IS, como en el caso del área de estudio.

En el diagrama de Piper se muestran las 5 muestras colectadas durante la época de lluvia. En la figura 4, se observa la variación química del agua en época de lluvia y estiaje, en el periodo de lluvia, las aguas subterráneas son ligeramente más bicarbonatadas (Ecuación 1). Sin embargo, el proceso de mezcla e interacción agua-roca no es homogéneo en toda la región, debido a que es una zona kárstica y estas características dependen del grado de fracturamiento de cada sitio. 
Tabla 1. Datos de campo de las muestras del área de estudio.

\begin{tabular}{|c|c|c|c|c|c|c|c|c|c|c|c|c|c|c|c|c|c|c|}
\hline No. & $\mathbf{X}$ & $\mathbf{Y}$ & $\mathbf{Z}$ & Temp & OD & OR & pH & CE & STD & $\mathrm{HCO}_{3}^{-}$ & $\mathrm{NO}_{3}^{-}$ & $\mathrm{Cl}^{-}$ & $\mathbf{F}^{-}$ & $\mathrm{SO}_{4}^{-2}$ & $\mathrm{Ca}^{+2}$ & $\mathbf{K}^{+}$ & $\mathrm{Mg}^{+2}$ & $\mathrm{Na}^{+}$ \\
\hline & UTM & UTM & $\mathbf{m}$ & ${ }^{\circ} \mathbf{C}$ & ppm & Mv & & $\mathbf{m S} / \mathbf{c m}$ & ppm & ppm & ppm & ppm & ppm & ppm & ppm & ppm & ppm & ppm \\
\hline $1 a$ & 511489 & 2428859 & 38 & 36 & 0.33 & -185 & 6.9 & 1660 & 1061 & 360 & 8 & 78.4 & 0.35 & 9 & 146 & 11.1 & 19.7 & 84.4 \\
\hline $2 a$ & 511944 & 2431591 & 40 & 26.8 & 6.55 & 88 & 6.7 & 1220 & 869 & 260 & 8 & 4.2 & 0.23 & 388 & 237 & 1.6 & 48.3 & 4.1 \\
\hline $3 \mathbf{a}$ & 505040 & 2423455 & 51 & 32.8 & 0.28 & -169 & 6.4 & 1080 & 771 & 300 & 9 & 3.9 & 0.43 & 320 & 195 & 1.9 & 45.2 & 9.4 \\
\hline $4 b$ & 505355 & 2412860 & 47 & 32.6 & 0.43 & -140 & 6 & 970 & 693 & 480 & 12 & 3.7 & 0.26 & 24 & 184 & 1.1 & 20.1 & 11.7 \\
\hline 5 & 502474 & 2403135 & 45 & 25.5 & 2.48 & 125 & 6.7 & 1590 & 1151 & 260 & 10 & 2.7 & 0.26 & 1013 & 349 & 1.8 & 59.1 & 4.2 \\
\hline 6 & 489592 & 2388416 & 912 & 20.7 & 6.73 & 106 & 7.6 & 260 & 186 & 140 & 9 & 1 & 0 & 8 & 59.7 & 0.4 & 1.4 & 0.5 \\
\hline $7 a$ & 495566 & 2398145 & 80 & 25.3 & 2.79 & 108 & 6.7 & 1580 & 1145 & 260 & 11 & 3.4 & 0.28 & 600 & 347 & 1.9 & 57.6 & 4.5 \\
\hline 8 & 498114 & 2367341 & 849 & 20.3 & 7.19 & 107 & 7.3 & 280 & 200 & 160 & 8 & 1 & 0 & 7 & 59.4 & 0.4 & 6.4 & 0.9 \\
\hline 9 & 498788 & 2365449 & 866 & 20.7 & 8 & 86 & 7.3 & 210 & 150 & 140 & 8 & 1.3 & 0 & 4 & 45.6 & 0.2 & 4.2 & 0.3 \\
\hline 10 & 502386 & 2372964 & 139 & 20.7 & 7.3 & 118 & 7.1 & 300 & 209 & 180 & 8 & 1.3 & 0 & 4 & 57.6 & 0.6 & 9 & 1.6 \\
\hline $11 \mathrm{a}$ & 492512 & 2411381 & 38 & 25.1 & 1.24 & 125 & 6.6 & 1390 & 1000 & 260 & 13 & 3.6 & 0.17 & 520 & 292 & 1.7 & 53.4 & 3.8 \\
\hline 12 & 463447 & 2476423 & 506 & 20.9 & 4.73 & 135 & 6.9 & 500 & 349 & 240 & 11 & 1.4 & 0 & 30 & 90.7 & 0.8 & 13.7 & 1.3 \\
\hline 13 & 461814 & 2475257 & 581 & 23.5 & 7.4 & 163 & 7 & 460 & 325 & 220 & 11 & 0.8 & 0 & 17 & 87.5 & 0.9 & 16.1 & 0.9 \\
\hline 14 & 495301 & 2510201 & 132 & 27.3 & 2.47 & 132 & 6.6 & 1220 & 871 & 180 & 11 & 4.8 & 0.27 & 400 & 234 & 2.7 & 45.2 & 8 \\
\hline 15 & 460470 & 2497953 & 521 & 28.4 & 7.27 & 140 & 7.9 & 1170 & 836 & 240 & 2 & 5.8 & 0.1 & 420 & 227 & 2.9 & 45.6 & 8.2 \\
\hline 16 & 454700 & 2496425 & 548 & 24.6 & 5.09 & 175 & 6.5 & 770 & 546 & 220 & 6 & 2.5 & 0.03 & 240 & 171 & 2 & 26.4 & 4.9 \\
\hline 17 & 480110 & 2430820 & 178 & 24.9 & 2.5 & 207 & 6.6 & 1190 & 851 & 280 & 5 & 1.7 & 0.19 & 380 & 287 & 1.4 & 38 & 2 \\
\hline 18 & 483192 & 2410058 & 105 & 25.5 & 3.8 & 231 & 6.5 & 1050 & 745 & 260 & 8 & 1.9 & 0.09 & 360 & 243 & 1.5 & 36.5 & 3.1 \\
\hline 19 & 456573 & 2424998 & 429 & 25.9 & 5.82 & 238 & 6.9 & 1090 & 773 & 200 & 12 & 14.1 & 0.25 & 360 & 212 & 3.7 & 47 & 18.8 \\
\hline 20 & 456759 & 2425061 & 436 & 25.6 & 7.39 & 226 & 7.4 & 1180 & 833 & 180 & 15 & 34.6 & 0.27 & 640 & 312 & 6.9 & 76.9 & 32.9 \\
\hline 21 & 456807 & 2425027 & 357 & 26.7 & 6.36 & 244 & 7.3 & 1590 & 1143 & 180 & 14 & 45.2 & 0.29 & 640 & 314 & 7.4 & 73.4 & 35.6 \\
\hline 22 & 457009 & 2425357 & 394 & 26.3 & 6.05 & 243 & 7 & 1540 & 1140 & 180 & 14 & 38.2 & 0.33 & 640 & 298 & 7.1 & 75.8 & 33.8 \\
\hline 23 & 456972 & 2425326 & 436 & 26.9 & 5.46 & 227 & 7 & 1570 & 1137 & 200 & 12 & 34.6 & 0.3 & 580 & 314 & 7.1 & 74.9 & 35 \\
\hline 24 & 459333 & 2428861 & 369 & 24.3 & 5.7 & 231 & 6.8 & 800 & 570 & 240 & 14 & 16.2 & 0 & 100 & 172 & 2.7 & 26.7 & 11.2 \\
\hline 25 & 413884 & 2408101 & 849 & 30.7 & 1.71 & 242 & 6.4 & 1730 & 1255 & 220 & 15 & 16 & 0.29 & 780 & 406 & 5.4 & 89.3 & 15.4 \\
\hline 26 & 393773 & 2417800 & 1006 & 30 & 1.27 & 229 & 6.6 & 1670 & 1210 & 280 & 15 & 5.2 & 0.44 & 680 & 384 & 4.9 & 71.8 & 15 \\
\hline 27 & 393632 & 2417783 & 1007 & 29.7 & 0 & 231 & 6.5 & 1640 & 1174 & 260 & 15 & 4.4 & 0.39 & 700 & 371 & 5.1 & 71.6 & 15.2 \\
\hline $1 b$ & 511489 & 2428859 & 38 & 31.19 & 0.61 & 102.8 & 6.79 & 767 & 384 & 276 & 12 & 35.6 & & 25 & 137.2 & 1.85 & 5.41 & 47 \\
\hline $2 \mathbf{b}$ & 511944 & 2431591 & 40 & 25.75 & 7.24 & 75.9 & 7.02 & 696 & 349 & 255 & 9 & 1.2 & & 120 & 129.9 & 0.71 & 13.08 & 2.83 \\
\hline $\mathbf{3 b}$ & 505040 & 2423455 & 51 & 32.72 & 0.12 & -322 & 6.78 & 1145 & 573 & 285 & 10 & 3.4 & & 40 & 165.5 & 1.76 & 39.22 & 9.15 \\
\hline $4 b$ & 505355 & 2412860 & 47 & 30.98 & 0.1 & -261.6 & 6.52 & 927 & 464 & 426 & 11 & 0.7 & & 33 & 158.5 & 0.77 & 12.92 & 9.7 \\
\hline $7 b$ & 495566 & 2398145 & 80 & 21.97 & 7.44 & 8.6 & 7.57 & 601 & 300 & 195 & 9 & 2.5 & & 3 & 104.8 & 0.51 & 14.16 & 1.11 \\
\hline $11 b$ & 492512 & 2411381 & 38 & 20.52 & 7.86 & 1.8 & 7.75 & 286 & 143 & 165 & 9 & 1.3 & & 5 & 54.7 & 0.41 & 4.4 & 0.64 \\
\hline
\end{tabular}

\subsection{Modelación Hidrogeoquímica}

Los principales flujos subterráneos en el área de estudio van de $\mathrm{W}-\mathrm{E}$. Debido a que la zona de estudio está sumamente fracturada, es posible que un número importante de estas fracturas estén comunicadas hidráulicamente, como lo evidencian los manantiales de la región. Para comprobar la conectividad hidráulica del sistema de fallas y fracturas en la Sierra Oriental, se eligieron 4 secciones E-W 1) Apesco-Huchihuayan, 2) Unión de Guadalupe-Tambaque, 3) Rioverde-Santa Anita, 4) El Salto-Minas Viejas, en los que se desarrollaron modelos hidrogeoquímicos para entender esta conectividad en la zona kárstica de la Huasteca Potosina. Las secciones modeladas fueron seleccionadas y ubicadas sobre líneas de flujo que son perpendiculares a las líneas equipotenciales (Figura 1).

En la modelación hidrogeoquímica inversa las principales ecuaciones que gobiernan los procesos de interacción aguaroca en la zona kárstica del área de estudio son:

Disolución de carbonatos:

$\mathrm{CO}_{2}+\mathrm{H}_{2} \mathrm{O} \leftrightarrow \mathrm{H}_{2} \mathrm{CO}_{3} \leftrightarrow \mathrm{HCO}_{3}^{-}+\mathrm{H}^{+} \leftrightarrow \mathrm{CO}_{3}^{-2}+\mathrm{H}^{+}$

Disolución de Calcita:

$$
\mathrm{CaCO}_{3} \leftrightarrow \mathrm{Ca}^{+2}+\mathrm{CO}_{3}^{-2}
$$

Disolución de Dolomita y formación de Calcita:

$$
\mathrm{Ca} \mathrm{Mg}\left(\mathrm{CO}_{3}\right)_{2} \leftrightarrow 2 \mathrm{CO}_{3}^{-2}+\mathrm{Mg}^{+2}+\mathrm{Ca}^{+2}
$$




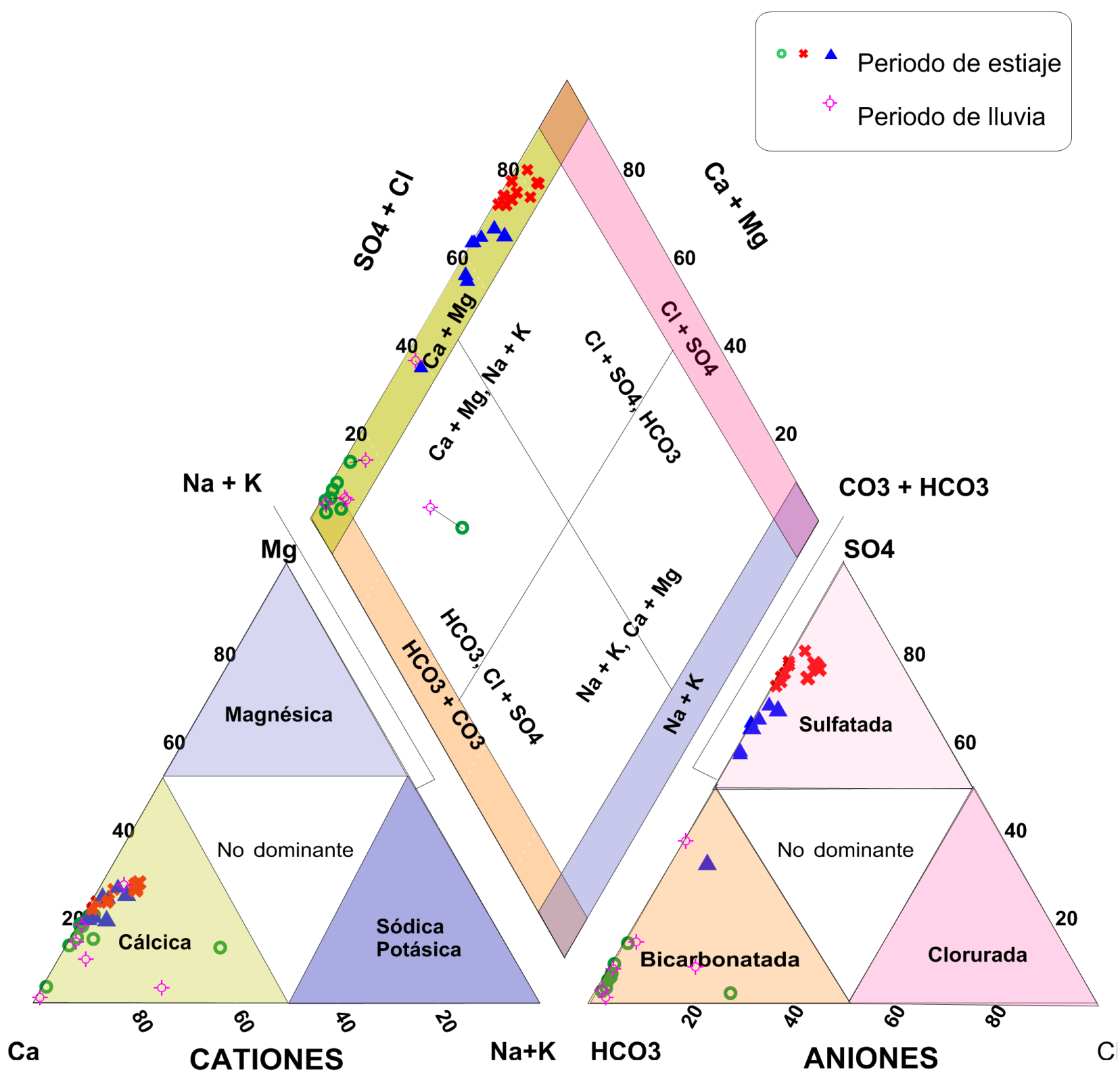

Figura 4. Diagrama de Piper que muestra los tipos de agua en el área de estudio.

Disolución de Yeso:

$$
\mathrm{CaSO}_{4} \cdot 2 \mathrm{H}_{2} \mathrm{O} \leftrightarrow \mathrm{Ca}^{+2}+\mathrm{SO}_{4}^{-2}+2 \mathrm{H}_{2} \mathrm{O}
$$

Reducción de sulfatos con Materia Orgánica:

$$
2 \mathrm{CH}_{2} \mathrm{O}+\mathrm{SO}_{4}^{-2} \leftrightarrow 2 \mathrm{HCO}^{-}+\mathrm{H}_{2} \mathrm{~S}
$$

Oxidación de pirita:

$$
\mathrm{FeS}_{2}+7 / 2 \mathrm{O}_{2}+\mathrm{H}_{2} \mathrm{O} \leftrightarrow \mathrm{Fe}^{2+}+2 \mathrm{SO}_{4}^{-2}+2 \mathrm{H}^{+}(5 \mathrm{~b})
$$

$\mathrm{FeS}_{2}+15 / 4 \mathrm{O}_{2}+7 / 2 \mathrm{H}_{2} \mathrm{O} \leftrightarrow \mathrm{Fe}(\mathrm{OH})_{3}+2 \mathrm{SO}_{4}^{2-}+4 \mathrm{H}^{+}(5 \mathrm{c})$

Reducción del nitrato:

$5 \mathrm{CH}_{2} \mathrm{O}+4 \mathrm{NO}_{3}^{-} \leftrightarrow 2 \mathrm{NO}_{2}^{-2}+4 \mathrm{HCO}_{3}^{-}+\mathrm{CO}_{2}+3 \mathrm{H}_{2} \mathrm{O}(6)$

La modelación hidrogeoquímica se realizó con
PHREEQC (Parkhurst et al., 1980), que genera cientos de modelos, de los cuales se eligieron sólo tres que cumplen con los criterios de selección, la cual se basa principalmente en la mínima incertidumbre $(<0.05)$ con la que se condiciona el ingreso de los datos. También considera las reacciones termodinámicas afines a la geología del las secciones modeladas (marcadas en negritas) de las Tablas 2, 3, 4 y 5; así como, la congruencia de estas reacciones con los deltas iónicos (Figuras 5, 6, 7,8) de los parámetros fisicoquímicos introducidos al modelo.

En el área de estudio se identificaron principalmente tres flujos subterráneos, uno local, otro intermedio y el tercero regional. El primero esta asociado a la recarga local y el tercero es un flujo más evolucionado con mayor tiempo 


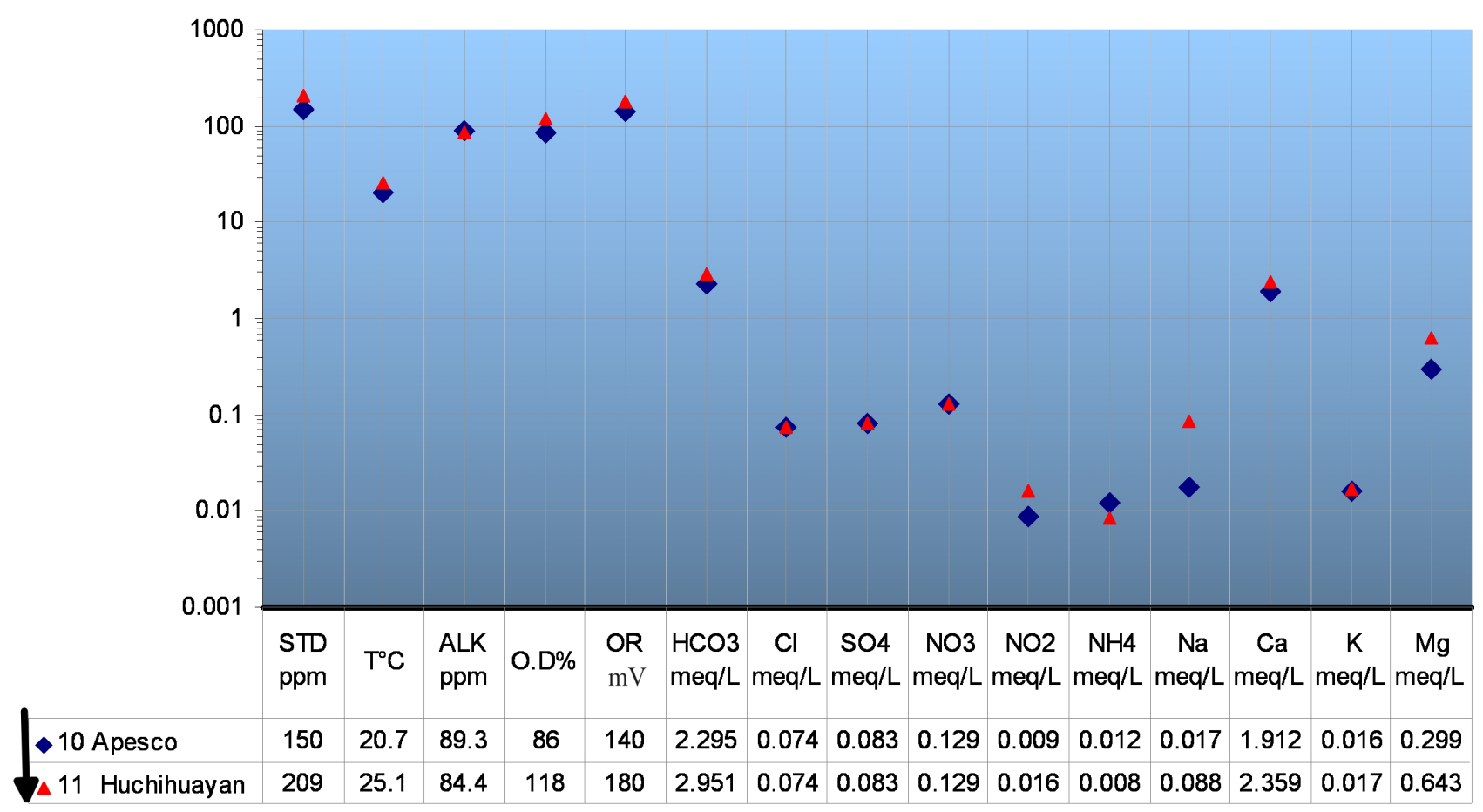

Figura 5. Variación de parámetros fisicoquímicos de la sección Apesco-Huichihuayan, la flecha indica el sentido del flujo.

de residencia y mayor distancia recorrida, entre ambos se encuentra el flujo intermedio (Figura 3 y 4).

La primera sección modelada está influenciada por el flujo local (Apesco-Huichihuayan), la sección Unión de Guadalupe-Tambaque alcanza flujos intermedios, y en ambas secciones el proceso dominante es la mezcla y en las secciones Rioverde-Santa Anita y El Salto-Minas Viejas, prevalece el flujo regional, con interacción agua-roca como proceso dominante. Esto se puede observar en la cantidad de especies involucradas en los modelos seleccionados (Tablas 2, 3, 4 y 5).

\subsubsection{Secciones modeladas}

\section{1) Apesco-Huichihuayan}

El flujo local se produce en calizas kársticas de la Formación El Abra, esta sección se localiza al sur de la zona de la Huasteca, en donde el Manantial de Apesco está en la zona montañosa con una elevación de $866 \mathrm{msnmm}$ y el manantial de Huchihuayan en la zona baja a 149 msnmm. La distancia en línea recta entre ambos sitios es de aproximadamente $7 \mathrm{~km}$. En este trayecto se incrementaron todos los parámetros fisicoquímicos lo cual involucra disolución de minerales (Figura 5). Los manantiales de Apesco y Huichihuayan representan flujos locales bajo condiciones oxidantes.

En la Tabla 2, se muestran los tres modelos principales de transferencia de masa, de acuerdo con los resultados obtenidos, el modelo 2 es el que mejor reproduce los procesos hidrogeoquímicos de la sección.

El modelo 2 predice la formación de calcita $(-9.320 \mathrm{E}-$
Tabla 2.- Modelos producidos por PHREEQC para el segmento de flujo de Apesco a Huichihuayan en la zona de la Huasteca (Unidades en mmoles/L).

\begin{tabular}{lccc}
\hline $\begin{array}{c}\text { Apesco - } \\
\text { Huchihuayan }\end{array}$ & Modelo 1 & Modelo 2 & Modelo 3 \\
\hline Anhidrita & $-1.24 \mathrm{E}-01$ & $\mathbf{3 . 7 1 E - 0 4}$ & $8.27 \mathrm{E}-05$ \\
Calcita & $-6.40 \mathrm{E}-04$ & $\mathbf{- 9 . 3 2 E - 0 4}$ & $-6.44 \mathrm{E}-04$ \\
Celestita & $-5.34 \mathrm{E}-05$ & $\mathbf{- 5 . 3 4 E - 0 5}$ & $-5.34 \mathrm{E}-05$ \\
Calcedonia & $8.51 \mathrm{E}-06$ & $\mathbf{8 . 5 1 E - 0 6}$ & $8.51 \mathrm{E}-06$ \\
$\mathrm{CO}_{2}(\mathrm{~g})$ & $7.17 \mathrm{E}-04$ & $\mathbf{1 . 0 1 E - 0 3}$ & $7.21 \mathrm{E}-04$ \\
$\mathrm{Dolomita}_{2}$ & $5.24 \mathrm{E}-04$ & $\mathbf{5 . 2 4 E - 0 4}$ & $5.24 \mathrm{E}-04$ \\
$\mathrm{H}_{2} \mathrm{O}(\mathrm{g})$ & & $\mathbf{2 . 4 8 E - 0 1}$ & $2.48 \mathrm{E}-01$ \\
$\mathrm{Yeso}$ & $1.24 \mathrm{E}-01$ & & \\
$\mathrm{H}_{2} \mathrm{~S}(\mathrm{~g})$ & $-1.17 \mathrm{E}-05$ & & \\
$\mathrm{Halita}$ & $1.66 \mathrm{E}-07$ & $\mathbf{1 . 6 6 E - 0 7}$ & \\
$\mathrm{O}_{2}(\mathrm{~g})$ & $4.33 \mathrm{E}-04$ & & $4.33 \mathrm{E}-04$ \\
Sulfuro & & $\mathbf{- 3 . 0 4 E - 0 4}$ & $-1.57 \mathrm{E}-05$ \\
\hline
\end{tabular}

04), y celestita (-5.34E-05); la disolución de anhidrita (3.71E-04), calcedonia (8.51E-06), halita (1.66E-07) y dolomita (5.24E-04). La reacción de sulfato $\left(\mathrm{SO}_{4}{ }^{2-}\right)$ con materia orgánica en medio ácido $\left(\mathrm{H}^{+}\right)$ó bien en presencia de $\mathrm{H}^{+}$, produce $\mathrm{CO}_{2}$, agua y sulfuro.

En el trayecto el sulfato se reduce con materia orgánica (Ec. 5a) esta reacción puede llevarse a cabo posiblemente debido a la acción bacteriana.

2) Unión de Guadalupe - Tambaque

Esta sección se localiza en la parte sur del área de 
estudio. Este segmento representa un flujo intermedio en la zona de recarga que se encuentra en la Sierra El Nacimiento a 912 msnmm y la descarga al sur de Ciudad Valles a 80 msnmm. El flujo tiene lugar en calizas cársticas de la Formación El Abra y en calizas arcillosas de la Formación Agua Nueva en la zona del valle.

El modelo 2 (Tabla 3) predice la disolución de calcita, fluorita, halita, sílice, azufre y formación de dolomita. Debido a la disolución de carbonatos, en el agua subterránea se tiene un incremento de calcita (1.40E-03), fluorita (7.38E-06), halita (6.78E-05), sílice (6.50E-05), azufre (8.07E-05). La precipitación de lluvia produce un aumento de dolomita en solución, mientras que en época de estiaje existe disminución de dolomita (-5.76E-05) por la formación

Tabla 3.- Modelos producidos por PHREEQC para el segmento de flujo de Unión de Guadalupe -Tambaque (Unidades en mmoles /L).

\begin{tabular}{lccc}
\hline $\begin{array}{l}\text { Union de Guadalupe - } \\
\text { Tambaque }\end{array}$ & Modelo1 & Modelo 2 & Modelo 3 \\
\hline Calcita & $1.29 \mathrm{E}-03$ & $\mathbf{1 . 4 0 E - 0 3}$ & $1.34 \mathrm{E}-03$ \\
$\mathrm{CO}_{2}(\mathrm{~g})$ & $2.84 \mathrm{E}-03$ & & $2.79 \mathrm{E}-03$ \\
Dolomita & & $\mathbf{- 5 . 7 6 E - 0 5}$ & \\
Fluorita & $7.38 \mathrm{E}-06$ & $\mathbf{7 . 3 8 E - 0 6}$ & $7.38 \mathrm{E}-06$ \\
Halita & $6.78 \mathrm{E}-05$ & $\mathbf{6 . 7 8 E - 0 5}$ & $6.78 \mathrm{E}-05$ \\
$\mathrm{SiO}_{2}(\mathrm{a})$ & $6.50 \mathrm{E}-05$ & $\mathbf{6 . 5 0 E}-05$ & $1.03 \mathrm{E}-04$ \\
$\mathrm{Sulfuro}$ & $8.07 \mathrm{E}-05$ & $\mathbf{8 . 0 7 E - 0 5}$ & $8.07 \mathrm{E}-05$ \\
Crisotilo & & & $-1.92 \mathrm{E}-05$ \\
\hline
\end{tabular}

del mineral, durante su formación se libera $\mathrm{CO}_{2}(2.84 \mathrm{E}-03)$, aunque parte de este $\mathrm{CO}_{2}$ también puede ser aportado por el carbono orgánico procedente del suelo vegetal.

En la Figura 6 se observan las principales variaciones en $\mathrm{pH}$, conductividad eléctrica $(\mathrm{CE})$, sólidos totales disueltos (STD), Alcalinidad, sulfatos $\left(\mathrm{SO}_{4}\right)$ y $\mathrm{Ca}$, entre la muestra que va de Unión de Guadalupe a Tambaque, en todos los casos hubo incremento de estos parámetros fisicoquímicos.

En el trayecto entre Unión de Guadalupe a Tambaque, hay incremento de los iones mayores $\left(\mathrm{SO}_{4}^{-2}, \mathrm{Cl}^{-}, \mathrm{HCO}_{3}^{-}\right.$, $\left.\mathrm{NO}_{3}^{-}, \mathrm{Ca}^{+2}, \mathrm{Mg}^{+2}, \mathrm{Na}^{+}, \mathrm{K}^{+}\right)$y parámetros fisicoquímicos $(\mathrm{CE}$, $\mathrm{STD}, \mathrm{pH}, \mathrm{T}, \mathrm{OD}$ y ORP), lo cual indica que la disolución de minerales fue el principal proceso.

\section{3) Rioverde-Santa Anita}

La sección 3 se localiza en la Zona Media del área de estudio. Esta sección conecta al manantial de Rioverde a una elevación de $1007 \mathrm{msnmm}$ con Santa Anita de menor elevación (178 msnmm). En la Zona Media el agua subterránea del flujo regional interacciona con formaciones evaporíticas de yesos, en tanto que hacia la zona Huasteca la circulación se desarrolla en calizas cársticas de la Formación El Abra.

En esta sección hay ganancia de $\mathrm{CO}_{2}$ por la formación de $\mathrm{HCO}_{3}^{-}$por lo que aumenta la alcalinidad como se muestra en la Figura 7, donde el flujo va de un tipo de agua sulfatada cálcica $\left(\mathrm{Ca}-\mathrm{SO}_{4}\right)$ a una bicarbonatada cálcica $\left(\mathrm{Ca}-\mathrm{HCO}_{3}\right)$. En el trayecto de Rioverde a Santa Anita, hay un incremento de los iones mayores $\left(\mathrm{SO}_{4}^{-2}, \mathrm{Cl}^{-}, \mathrm{HCO}_{3}^{-}, \mathrm{NO}_{3}^{-}, \mathrm{Ca}^{+2}, \mathrm{Mg}^{+2}\right.$, $\mathrm{Na}^{+}, \mathrm{K}^{+}$) y los parámetros fisicoquímicos (CE, STD, $\mathrm{pH}$, $\mathrm{T}$, OD y PR), lo cual indica que la disolución de minerales

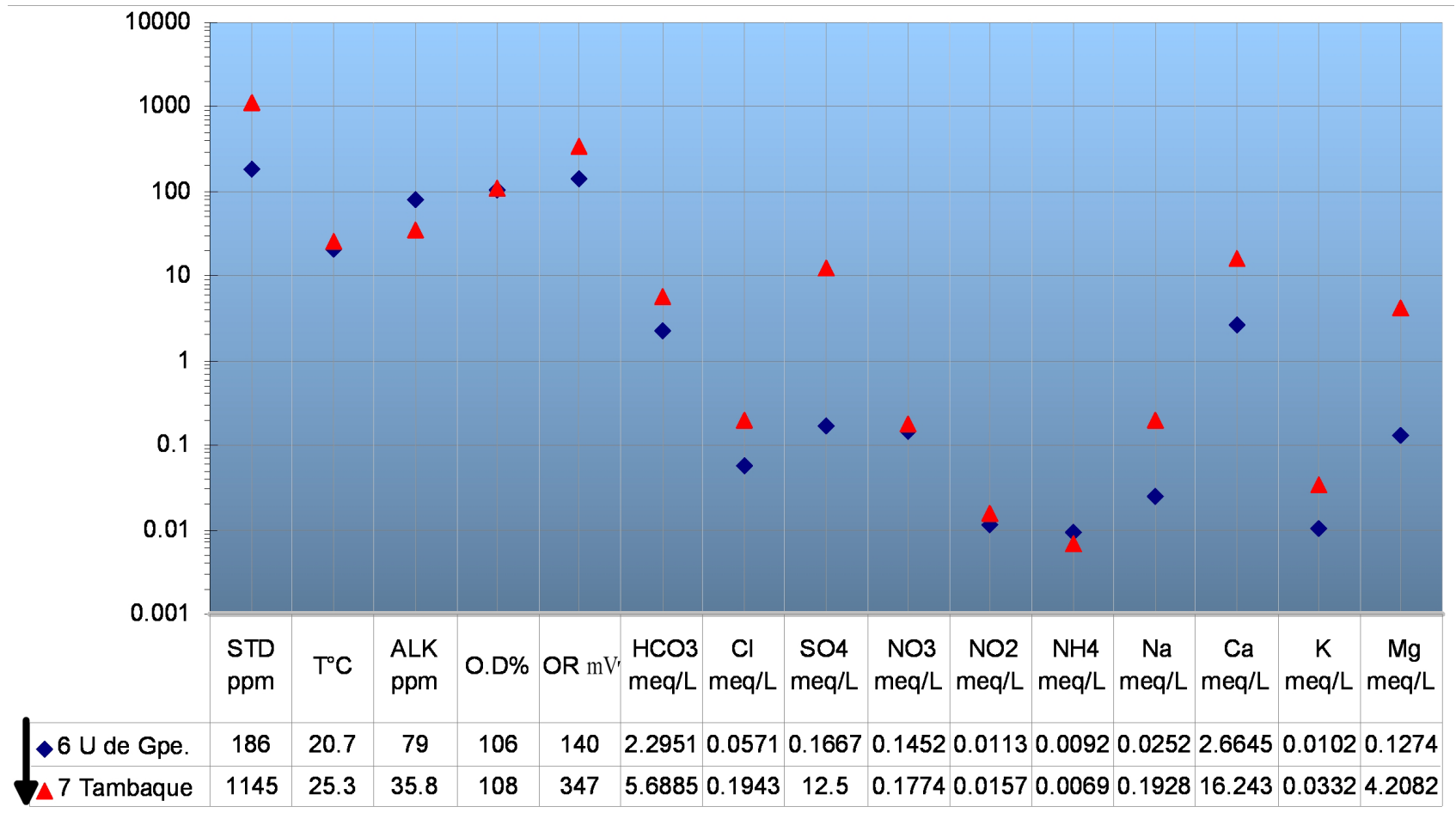

Figura 6. Variación de parámetros fisicoquímicos de la sección Unión de Guadalupe-Tambaque. 


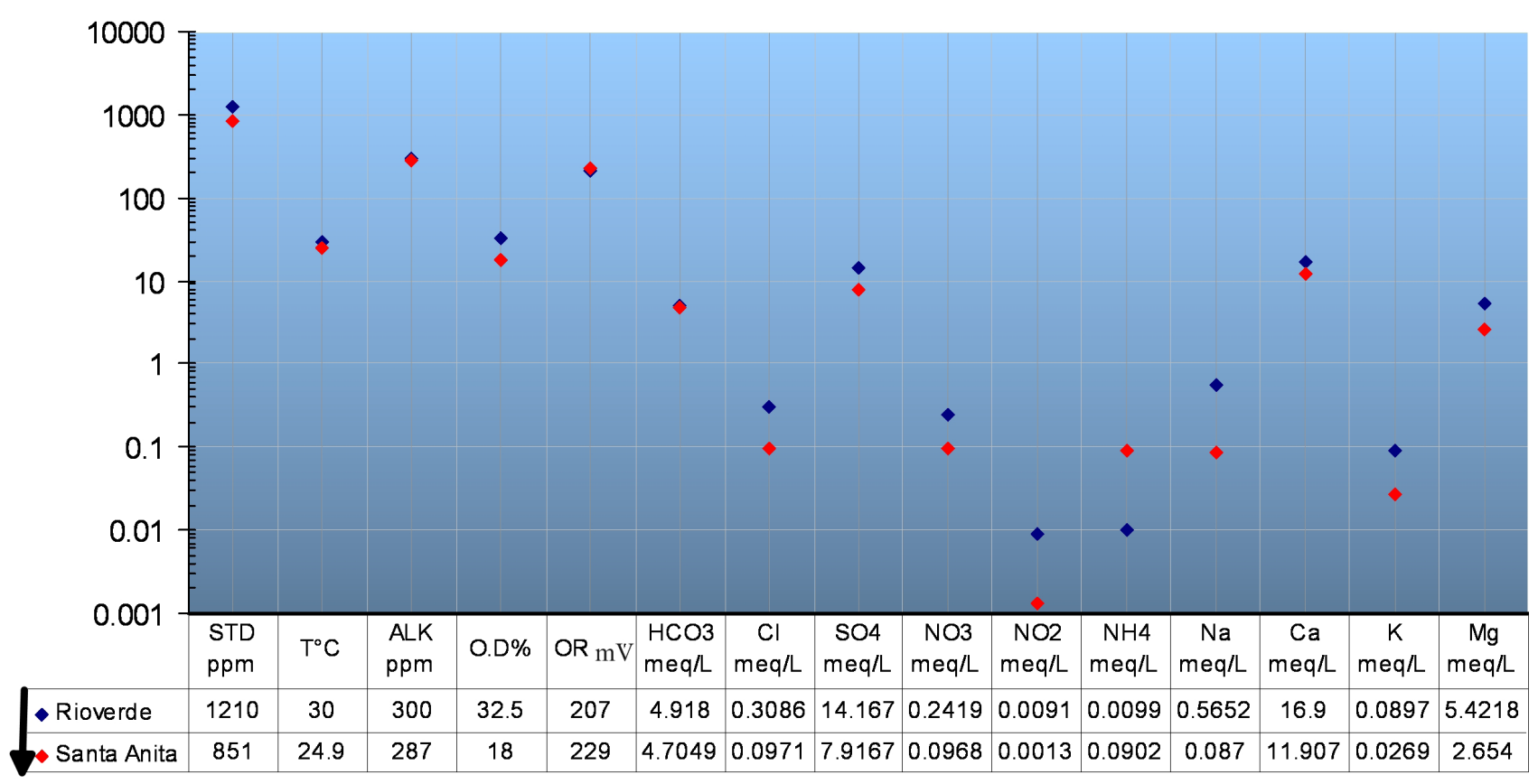

Figura 7. Variación de parámetros fisicoquímicos de la sección Rioverde-Santa Anita.

fue el principal proceso que ocurre a lo largo del trayecto del flujo subterráneo.

Para esta sección 3, el modelo 2 (Tabla 3) predice la precipitación de yeso, cuarzo, dolomita, estroncianita, y la disolución de halita. La anhidrita y calcita se encuentran en una zona conocida como metaestable, muy cercana a su precipitación (Ec. 1); por lo cual se encuentra anhidrita en disolución y precipitación de calcita.

Debido a que el yeso se encuentra en una zona metaestable, éste puede disolverse o precipitarse, dependiendo de las condiciones fisicoquímicas (Ec. 3). La presencia de calcio y magnesio en forma de carbonatos favorece la precipitación de dolomita, debido a que ésta tiene un índice de formación mayor que otras fases, como la calcita que se forma en menor proporción.

En la trasferencia se perdió yeso (-7.23E-02), $\mathrm{CO}_{2}$ (-2.56E-03), cuarzo (-4.83E-05), dolomita (-2.87E-03), estroncianita (-4.68E-05) y halita (-1.72E-04). Por otro lado hubo ganancia de calcita (4.39E-03), anhidrita (6.83E-02).

En la Figura 7 se observan las variaciones importantes en ORP, CE, STD, $\mathrm{SO}_{4}^{-2}$ y $\mathrm{Ca}^{+2}$, el flujo va de la media Luna en Rioverde a Santa Anita, en todos los casos hubo disminución de estos parámetros fisicoquímicos.

\section{4) El Salto- Minas Viejas}

La sección 4, se localiza al norte del área de estudio, conecta al manantial de Minas Viejas en la zona montañosa con el manantial El Salto en el Valle del Naranjo. En esta sección el agua circula a través de rocas carbonatadas de la Formación El Abra. Aunque en la figura de flujo subterráneo entre el Salto y Minas Viejas muestra poco gradiente, hay evidencia en el flujo superficial de tal conexión hidráulica, debido a que el río que nace en el Salto desaparece cerca de Minas Viejas a través de cavidades de disolución, por esta razón se consideró realizar la modelación hidrogeoquímica.

El modelo 2 (Tabla 4) predice la disolución de calcita, pirita y cuarzo; así como, precipitación de celestita, dolomita, FeS, yeso, halita, jarosita.

En la Figura 8 se observan las principales variaciones en $\mathrm{pH}, \mathrm{CE}, \mathrm{STD}$, Alcalinidad, $\mathrm{SO}_{4}^{-2} \mathrm{y} \mathrm{Ca}^{+2}$, entre la muestra que va de El Salto a Minas Viejas, en todos los casos hubo incremento de estos parámetros fisicoquímicos.

En este sitio es donde se puede observar una mayor precipitación de dolomita, yeso, halita, que al incorporar estos elementos ocurren las reacciones señaladas en las ecuaciones $4 \mathrm{~b}$ y c, dando lugar a la formación de pirita.

La disolución de la caliza incorpora $\mathrm{Ca}^{+2} \mathrm{y} \mathrm{CO}_{3}^{-2}$ al agua, debido a esto es más alto el contenido de cationes y aniones en el Salto que en Minas Viejas. Debido a la disolución e incorporación al agua subterránea se tiene un incremento en calcita $(1.11 \mathrm{E}+02)$, pirita $1.11 \mathrm{E}+02$ y cuarzo $(4.50 \mathrm{E}-$ $05)$. Debido a precipitación, la solución pierde celestita (-1.68E-04), halita (-8.36E-04), dolomita (-8.82E-03), FeS $(-1.11 \mathrm{E}+02)$, yeso $(-1.11 \mathrm{E}+02)$, halita $(-8.36 \mathrm{E}-04)$ y jarosita (-3.51E-04). Durante su formación se libera $\mathrm{CO}_{2}$ $(-1.11 \mathrm{E}+02)$.

\section{Conclusiones}

Con la modelación inversa de 4 secciones con posible conexión hidráulica por medio de fracturas, se logran identificar los procesos hidrogeoquímicos que ocurren en 
el agua subterránea.

Se identificaron dos principales tipos de agua: uno bicarbonatado cálcica, debido a interacción con rocas carbonatadas como calizas y dolomías; otro que se relaciona con un proceso de interacción agua-roca en yesos y anhidrita, que le dan un carácter sulfatado cálcica.

En general la modelación hidrogeoquímica sugiere que el principal proceso que domina en el flujo subterráneo es la interacción agua roca y la mezcla con agua de reciente infiltración.

Tabla 4. Modelos producidos por PHREEQC para el segmento de flujo de Rioverde-Santa Anita (Unidades en mmoles /L).

\begin{tabular}{lccc}
\hline $\begin{array}{l}\text { Rioverde- Santa } \\
\text { Anita }\end{array}$ & Modelo1 & Modelo2 & Modelo 3 \\
\hline Yeso & $1.98 \mathrm{E}+01$ & $\mathbf{- 7 . 2 3 E - 0 2}$ & $1.98 \mathrm{E}+01$ \\
$\mathrm{CO}_{2}(\mathrm{~g})$ & $3.88 \mathrm{E}-03$ & $\mathbf{- 2 . 5 6 E - 0 3}$ & $3.88 \mathrm{E}-03$ \\
Calcita & $5.60 \mathrm{E}-04$ & $\mathbf{4 . 3 9 E - 0 3}$ & $5.43 \mathrm{E}-04$ \\
$\mathrm{H}_{2} \mathrm{O}(\mathrm{g})$ & & $\mathbf{- 2 . 7 6 E}+\mathbf{0 1}$ & \\
Cuarzo & $6.90 \mathrm{E}-05$ & $\mathbf{- 4 . 8 3 E - 0 5}$ & $6.90 \mathrm{E}-05$ \\
Anhidrita & $-1.98 \mathrm{E}+01$ & $\mathbf{6 . 8 3 E - 0 2}$ & $-1.98 \mathrm{E}+01$ \\
Dolomita & $7.20 \mathrm{E}-04$ & $\mathbf{- 2 . 8 7 E - 0 3}$ & $7.20 \mathrm{E}-04$ \\
Estroncianita & & $\mathbf{- 4 . 6 8 E - 0 5}$ & $1.70 \mathrm{E}-05$ \\
Sulfuro & $-1.02 \mathrm{E}-07$ & & $-1.02 \mathrm{E}-07$ \\
Halita & $6.05 \mathrm{E}-06$ & $\mathbf{- 1 . 7 2 E - 0 4}$ & \\
Pirita & $4.35 \mathrm{E}-08$ & & $4.35 \mathrm{E}-08$ \\
\hline
\end{tabular}

En el trayecto de Rioverde a Santa Anita, la modelación hidrogeoquímica inversa muestra que en el trayecto ocurrió precipitación de yeso, sílice, dolomita, estroncianita y halita en tanto que se disolvió anhidrita y calcita. El modelo predice la disolución de calcita, pirita y cuarzo; así como,

Tabla 5. Modelos producidos por PHREEQC para el segmento de flujo de Salto - Minas Viejas (Unidades en mmoles /L).

\begin{tabular}{lccc}
$\begin{array}{l}\text { Salto- Minas } \\
\text { Viejas }\end{array}$ & Modelo1 & Modelo2 & Modelo3 \\
\hline Anhidrita & & & $1.11 \mathrm{E}+02$ \\
Barita & & & $-6.99 \mathrm{E}-07$ \\
Calcita & $1.11 \mathrm{E}+02$ & $\mathbf{1 . 1 1 E}+\mathbf{0 2}$ & $7.66 \mathrm{E}-03$ \\
Celestita & $-1.68 \mathrm{E}-04$ & $\mathbf{- 1 . 6 8 E - 0 4}$ & $-1.68 \mathrm{E}-04$ \\
$\mathrm{CO}_{2}(\mathrm{~g})$ & $-1.11 \mathrm{E}+02$ & $\mathbf{- 1 . 1 1 E}+\mathbf{0 2}$ & $-7.52 \mathrm{E}-03$ \\
Dolomita & $-8.82 \mathrm{E}-03$ & $\mathbf{- 8 . 8 2 E - 0 3}$ & $-8.82 \mathrm{E}-03$ \\
FeS(ppt) & $1.11 \mathrm{E}+02$ & $\mathbf{- 1 . 1 1 E}+\mathbf{0 2}$ & $-5.55 \mathrm{E}-05$ \\
Yeso & $-1.11 \mathrm{E}+02$ & $\mathbf{- 1 . 1 1 E}+\mathbf{0 2}$ & $-1.11 \mathrm{E}+02$ \\
Halita & $-8.36 \mathrm{E}-04$ & $\mathbf{- 8 . 3 6 E - 0 4}$ & $-8.36 \mathrm{E}-04$ \\
Hematita & $-5.55 \mathrm{E}+01$ & & $5.54 \mathrm{E}-04$ \\
Jarosita-K & $-3.51 \mathrm{E}-04$ & $\mathbf{- 3 . 5 1 E - 0 4}$ & $-3.51 \mathrm{E}-04$ \\
$\mathrm{O}_{2}(\mathrm{~g})$ & $2.50 \mathrm{E}+02$ & $\mathbf{1 . 6 6 E}+\mathbf{0 2}$ & $-1.14 \mathrm{E}-03$ \\
Pirita & & $\mathbf{1 . 1 1 E}+\mathbf{0 2}$ & \\
Quartz & $4.50 \mathrm{E}-05$ & $\mathbf{4 . 5 0 E}-\mathbf{0 5}$ & $4.50 \mathrm{E}-05$ \\
\hline & & &
\end{tabular}

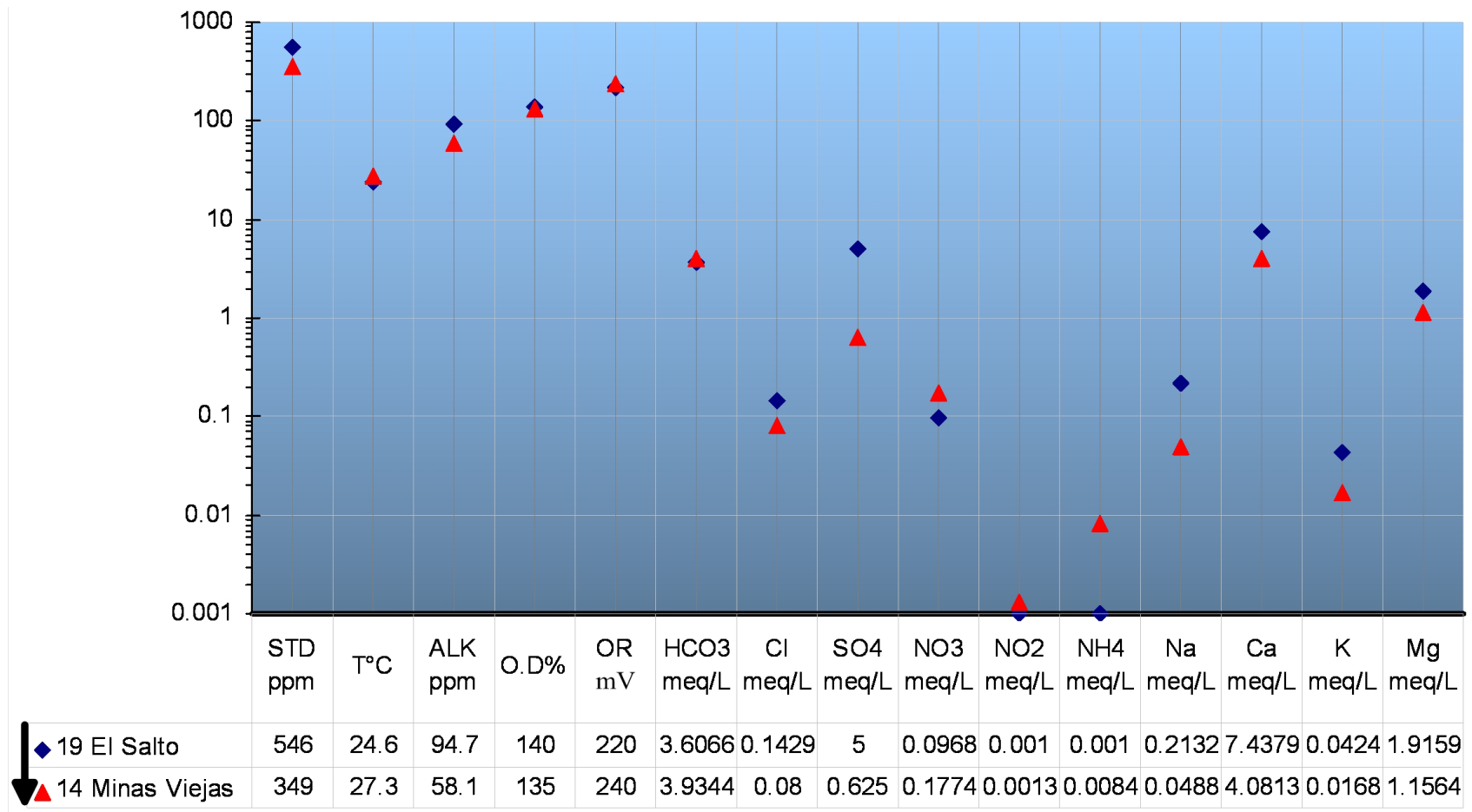

Figura 8. Variación de parámetros fisicoquímicos de la sección Salto- Minas Viejas. 
precipitación de celestita, dolomita, FeS, yeso, halita y jarosita.

En el flujo subterráneo de Apesco a Huichihuayan el modelo considera precipitación de anhidrita, aragonita, calcita, halita y celestita; así como, disolución de yeso, calcedonia y dolomita, el proceso gana $\mathrm{CO}_{2}$ (g) debido a la reacción de $\mathrm{SO}_{4}^{-2}$ con materia orgánica en presencia de $\mathrm{H}$.

En la evolución hidrogeoquímica de Unión de Guadalupe a Tambaque la modelación inversa indica la disolución de calcita, fluorita, halita, sílice y azufre; así como precipitación de dolomita.

En la sección El Salto- Minas Viejas, el modelo predice la disolución de calcita, pirita y cuarzo; así como, precipitación de celestita, dolomita, FeS, yeso, halita y jarosita.

La modelación hidrogeoquímica resultó una herramienta económica, útil y eficiente para evidenciar la conexión hidráulica entre cuencas y subcuencas hidrogeológicas e identificar los procesos naturales durante su evolución.

\section{Referencias}

André, L., Franceschi, M., Pouchan, P., Atteia, O., 2005, Using geochemical data and modelling to enchance the understanding of groundwater flow in a regional deep aquifer, Aquitaine Basin, south-west of France: Journal of Hydrology, 305, 40-62.

Apello, C.A., Postma, D., 1996, Geochemistry, groundwater and pollution: Rotterdam, A. A. Balkema, 536p.

Carranco-Lozada, S.E., 2011, Evaluación de la calidad química del agua subterránea en el acuífero cárstico de San Luis Potosí: México, Guanajuato, Universidad de Guanajuato, Tesis de Licenciatura, 79 p.

Carrillo, M.M., 1981, Contribución al estudio geológico del Macizo Calcáreo el Doctor, Estado de Querétaro: Universidad Nacional Autónoma de México, Revista del Instituto de Geología, 5 (1), 25-29.

Consejo de Recursos Minerales (CRM), 1992, Monografía geológicominera del estado de San Luis Potosí: México, SEMIP, Publicación M-7e, $218 \mathrm{p}$.

Helgeson, H.C., Brown, T.H., Nigrini, A., Jones, T.A., 1970, Calculations of mass transfer in geochemical processes involving aqueous solutions: Geochimica et Cosmochimica Acta, 34, 569-592.
Hereford, G., Keating, H., Guthrie, Jr. D., Chen, Z., 2007, Reactions and reaction rates in the regional aquifer beneath the Pajarito Plateau, north-central New Mexico, USA: Environmental Geology, 52, 965-977.

Hidalgo, C., Cruz-Sanjulián, J., 2001, Groundwater composition, hydrochemical evolution and mass transfer in a regional detrital aquifer (Baza Basin, Southern Spain): Applied Geochemistry, 16, 745-758.

Muir, J.M., 1936, Geology of the Tampico Region, Mexico: American Association of Petroleum Geologists, Memoir, 280 p.

Padilla y Sánchez, R.J., 1985, Las estructuras de la curvatura de Monterrey y estados de Coahuila, Nuevo León, Zacatecas y San Luis Potosí: México, D.F., Universidad Nacional Autónoma de México, Revista del Instituto de Geología, 6, 1-20.

Parkhurst, D.L., Thorstenson, D.C., Plummer, L.N., 1980, PHREEQE- A Comúter program for geochemical Calculations. U.S. Geological Survey, Water Resources Investigations Report, 80-96.

Parkhurst D.L., Apello, C.A.J., 1999, User guide to PHREEQC (version 2)-a computer program for speciation, batch reaction, one dimensional transport, and inverse geochemical calculations: U.S. Geological Survey Water Resources Investigations Report, 99-4259.

Pérez-Corona, F.Y., 2011, Caracterización Geofísica de Ambientes Cársticos, Caso: Polje de Joya de Luna, San Luis Potosí, México: México, San Luis Potosí, Instituto Potosino de Investigación Científica y Tecnológica, A.C., Tesis de Maestría, 197 p.

Plummer, L.N., Back, W., 1980, The mass balance approach: application to interpreting the chemical evolution of hydrologic systems: American Journal of Science, 280, 130-142.

Roback, R.C., Johnson, T.M, McLing, T.L., Murrell, M.T., Luo, S., Ku, T-L, 2001, Uranium isotopic evidence for groundwater chemical evolution and flow patterns in the eastern Snake River Plain Aquifer, Idaho: Geological Society of America Bulletin, 113 (9), 1133-1141.

Ramos-Leal , J.A., Santacruz, G., Torres-Gaytan, D., Morán-Ramírez, J., López-Loera, H., 2010, Caracterización terrenos cársticos por métodos hidrogeoquímicos y geofísicos: Caso Zona de La Huasteca, S.L.P. Unión Geofísica Mexicana, Geos, 29 (1), 38.

Zapata-Zapata, J.L., Pérez-Benzor, J.A., 1979, Cartografía Hoja Peotillos, S.L.P.: México, San Luis Potosí, Universidad Autónoma de San Luis Potosí, Instituto de Geología y Metalurgia, Folleto Técnico 63, 30p.

Manuscrito recibido: Junio 3, 2011.

Manuscrito corregido recibido: Mayo 5, 2012.

Manuscrito aceptado: Junio 27, 2012. 